\title{
PENGARUH LINGKUNGAN KERJA FISIK DAN BUDAYA ORGANISASI TERHADAP KINERJA PT. SURI TANI PEMUKA
}

\author{
P.T. Gresika ${ }^{1}$, Trianasari ${ }^{2}$ \\ 1,2 Jurusan Manajemen, Universitas Pendidikan Ganesha, Singaraja \\ e-mail:tirzgrace@gmail.com,Trianasari@udiksha.ac.id
}

\begin{abstract}
Abstrak
Penulisan ini disusun untuk membuktikan adanya pengaruh lingkungan kerja fisik, budaya organisasi, dan lingkungan kerja terhadap performa karyawan PT. Suri Tani Pemuka. Penelitian ini masuk kedalam penelitian kuantitatif kausal desain, dengan metode pengumpulan data berupa survey. Populasi studi ini mencakup seluruh karyawan PT. Suri Tani Pemuka yang berjumlah 42 orang, dengan objek penelitian yaitu lingkungan kerja, budaya organisasi, dan performa karyawan. Teknik analisis data menggunakan analisis regresi linear berganda. Dari hasil penelitian diketahui bahwa budaya organisasi memiliki pengaruh positif dan signifikan terhadap performa karyawan, hal ini dapat dilihat nilai $p$-value $0,002<$ alpha 0,05 , dimana nilai sig lebih kecil dari nilai alpha 0,05 . Selain itu lingkungan kerja dan budaya organisasi memiliki pengaruh positif dan signifikan terhadap performa karyawan, hal ini dapat dilihat pada nilai koefisien determinasi Ryx1x2 yang menunjukkan angka 0,735 dengan tanda positif, dimana nilai p-value $0,000<$ alpha 0,05 , artinya nilai sig tersebut lebih kecil dari nilai alpha 0,05 .
\end{abstract}

Kata kunci: budaya organisasi, lingkungan kerja, performa karyawan

\section{Abstract}

This paper aimed to prove the influence of the physical work environment, culture of organization and work environment, on the performance of employees of PT.Suri Tani Pemuka. This research is a causal quantitative research design, with the data collection method is a survey. The population of this study included all employees of PT. Suri Tani Pemuka, 42 people, with the objects of this research are the work environment, culture of organization, and performance of the employee. This study used multiple linear regression analysis. The results of this research showed that culture of organization has a positive and significant effect on employee performance, it can be seen that the $p$ value is 0.002 <alpha 0.05 , it means that the sig value smaller than the alpha value of 0.05 . The work environment and culture of organization have a positive and significant effect on performance of the employee, it can be seen that the coefficient of determination Ryx1x2 is 0.735 which is positive, with a $p$-value of 0.000 <alpha 0.05 , it means that the sig value smaller than the alpha value 0.05 .

Keywords: culture of organization, performance of employees, work environment.

\section{Pendahuluan}

Performa adalah bentuk prestasi kerja yang diberikan karyawan kepada perusahaan yang menjadi acuan keberhasilan perusahaan untuk mencapai tujuan yang sudah ditetapkan (Wanjala dalam Sri Noviani:2018). Ada banyak faktor yang memengaruhi performa karyawan yang juga menjadi tantangan tersendiri bagi perusahaan. SDM memerlukan pengelolaan agar dapat berperforma baik. Adanya SDM berkualitas tanpa pengelolaan yang tepat dapat berdampak pada kegagalan perusahaan seperti penurunan atau rendahnya performa karyawan. Hal ini terlihat ketika karyawan tidak mampu menyelesaikan target pekerjaan dengan kualitas dan kuantitas sesuai dengan ketentuan perusahaan. Bernardin (dalam Robbins, 2006), mengemukakan ada enam parameter tolak ukur performa individu karyawan yaitu kualitas, kuantitas, efesiensi, efektifitas, kemandirian dan loyalitas kerja.

Satu dari beberapa faktor yang mempunyai dampak pada performa karyawan dalam mencapai tujuan organisasi yaitu lingkungan kerja yang baik dan memadai. Sunyoto (2012), mengemukakan bahwa lingkungan kerja merupakan semua hal yang terdapat di lingkungan para pekerja dan berpengaruh dalam melaksanakan tugas yang diberikan, seperti kebersihan, musik, penerangan, dan lainnya. Setiap perusahaan wajib mengikuti standar lingkungan kerja yang representative, tersemat dalam Keputusan Menteri Kesehatan Republik Indonesia 
Nomor 1405/MENKES/SK/XI/2002, yang mengatur ketentuan yang harus dipenuhi kantor atau industri untuk menciptakan lingkungan kerja yang sehat mencakup air, udara, limbah, pencahayaan, kebisingan, getaran, radiasi, faktor penyakit, persyaratan kesehatan lokasi, ruang dan bangunan, toilet dan instalasi. Ketentuan ini berlaku dalam lingkungan kantor individu maupun kelompok.

Menurut Sarplin dalam Riani (2011), budaya dalam lingkungan organisasi atau perusahaan dinilai sebagai faktor yang juga mempengaruhi baik atau buruknya sistem kerja karyawan. Budaya organisasi dianggap sebagai suatu kepercayaan, kebiasaan dan nilai yang saling terikat dengan sistem formula dalam menghasilkan norma-norma perilaku suatu organisasi, budaya kerja itu sendiri tercipta dari anggapan karyawan yang mencakup nilai keterbaruan, toleransi, resiko, tekanan pada tim, dan dukungan dari luar (Robin dalam Saputri 2019). Untuk itu perlunya manajer perusahaan memperhatikan langsung maupun tidak mengenai pengaruh budaya organisasi, dengan kata lain pengaplikasian budaya organisasi yang baik akan berefek baik juga terhadap perusahaan. Anderson dan Ackerman (dalam Wibowo, 2010:33), menunjukkan ada tiga belas indikator dalam kultur organisasi yaitu 1). gaya kepemimpinan; 2). Strategi komunikasi; 3). strategi pengambilan keputusan; 4). pemanfaatan informasi; 5). pemanfaatan komunikasi elektronik sebagai sarana untuk berbagi informasi, pengambilan keputusan, membangun hubungan; 6). tingkat klasifikasi; 7). standar dan harapan performa; 8). konsekuensi kegagalan; 9). norma dan perilaku; 10). ruang/susunan; 11). cerita, mitos, tradisi; 12). Kepahlawanan; 13). moto, bahasa, dan logo.

Lingkungan kerja fisik dan budaya organisasi secara khusus merupakan faktor penting bagi pelaku usaha di bidang pengolahan bahan makanan, karena berkaitan dengan higienitas. Sedarmayanti (2011) mengemukan bahwa ada delapan parameter lingkungan kerja fisik yaitu pencahayaan, temperature di ruang kerja, sirkulasi udara, tingkat kebisingan, dekorasi, baubauan, keamanan dan tata warna di tempat kerja. Performa perusahaan dapat menjadi buruk atau menurun, bila manajemen tidak memberikan perhatian pada kedua faktor tersebut. Refleksi dari fenomena ini ditemui saat wawancara dengan karyawan PT. Suri Tani Pemuka, perusahaan ini berlokasi di daerah Pemuteran Gerokgak merupakan satu-satunya perusahaan yang bergerak dalam pembudiayaan dan pengolahan udang Galah yang mempunyai Badan Hukum di Bali. Perusahaan ini berdiri sejak tahun 2008.

Saat ini. PT Suri Tani Pemuka telah memiliki banyak cabang yang berlokasi di Jakarta dan Banyuwangi. Perusahaan ini juga melakukan kerja sama dengan PT. Japfa yang merupakan perusahaan produsen makanan cepat saji asal Jepang, dengan adanya kerja sama tersebut PT. Suri Tani Pemuka menciptakan tuntutan yang besar pula.

Hasil observasi dan wawancara awal menunjukkan adanya fluktuasi tingkat ketercapaian target benih udang dalam kurun waktu 5 bulan, sebagaimana diilustrasikan pada Tabel 1 berikut:

Tabel 1. Data Target Produksi Benih Udang PT. Sari Tani Pemuka Tahun 2019

\begin{tabular}{clcc}
\hline Bulan & Target Benih/Siklus & Realisasi & $\begin{array}{c}\text { Persentase } \\
(\%)\end{array}$ \\
\hline Juli & 200.000 .000 butir & 114.785 .334 butir & $57 \%$ \\
Agustus & 200.000 .000 butir & 116.395 .000 butir & $58 \%$ \\
September & 200.000 .000 butir & 115.084 .493 butir & $57 \%$ \\
Oktober & 200.000 .000 butir & 110.453 .098 butir & $55 \%$ \\
November & 200.000 .000 butir & 110.620 .029 butir & $55 \%$
\end{tabular}

Sumber: Personalia PT. Suri Tani Pemuka (data diolah)

Dapat dilihat bahwa jumlah target benih yang harus dicapai oleh para karyawan, selalu sama yaitu sebanyak dua ratus juta benih. Walaupun target tidak ditingkatkan, karyawan tidak dapat mencapai target benih yang telah disepakati. Kondisi performa karyawan PT. Suri Tani Pemuka dapat dikatakan rendah. Hal ini terlihat dari tidak terpenuhinya target yang sudah ditentukan oleh perusahaan, dan kurangnya fasilitas yang tersedia di perusahaan. Kondisi ini 
tidak selaras dengan pendapat yang disampaikan oleh Mangkunegara (2006), performa (prestasi kerja), merupakan pencapaian kerja yang dinilai dari segi kulitas maupun kuantitas terhadap pencapaian seorang karyawan didalam melaksanakan pekerjaan sesuai kewajiban yang diberikan kepadanya.

Lebih jauh, hasil observasi dan wawancara pada personalia PT. Suri Tani Pemuka menunjukkan kurang baiknya kondisi lingkungan fisik pada ruang pembuahan hatchery dan pengolahan benih udang. Nyatanya masih ditemukan sarana dan prasarana tidak layak fungsi. Hal ini tidak sesuai dengan Sutrisno (dalam Arnasik: 2017) yang menerangkan bahwa lingkungan kerja fisik mencakup keseluruhan perkakas kerja yang tersedia di sekitar karyawan ketika melakukan pekerjaan yang berpengaruh terhadap pekerjaan.

Selanjutnya, hasil observasi awal menunjukkan kurang nyamannya lingkungan kerja juga nampak dalam ruangan para staff karyawan administrasi, di mana dalam satu ruangan ditempati 9 orang karyawan tetap dan 2 karyawan trainee. Hal ini diperkuat dengan hasil wawancara dari karyawan yang mengeluhkan tentang fasilitas yang sudah ada namun tidak berfungsi semestinya. Secara tidak langsung, hal ini memengaruhi ketepatan waktu karyawan dalam menyelesaikan pekerjaannya, dan secara tidak langsung sudah menjadi suatu kebiasaan atau budaya bagi para karyawan dalam bekerja.

Hasil observasi dan wawancara awal menunjukkan rendahnya performa karyawan PT. Suri Tani Pemuka yang diketahui dari target pencapaian benih dan adanya kebiasaan atau budaya kerja yang kurang baik dan yang didukung oleh lemahnya penerapan konsekuensi akan kegagalan target kerja, sehingga membuat mayoritas karyawan tidak segan untuk mengulangi kembali kesalahannya, sehingga akan berdampak dengan performa dari karyawan dalam perusahaan tersebut.

Pada research gap penelitian terdahulu diketahui Wanjiku dan Nickson (2014) mempunyai simpulan bahwa budaya organisasi yang baik dan teratur dapat membantu karyawan mengatur performa agar tujuan organisasi mudah dicapai. Hal ini dapat diartikan bahwa budaya organisasi mempengaruhi performa karyawan. Didukung dengan hasil penelitian Wahyuniardi dan Nurjaman (2018), di mana budaya organisasi memiliki pengaruh yang baik terhadap performa karyawan. Disisi lain, Vita (2014), menyimpulkan bahwa tidak ditemukannya pengaruh signifikan antara performa dengan kultur organisasi.

Adanya fenomena yang terjadi di PT. Suri Tani Pemuka mendasari perlunya diadakan penelitian. Studi ini bermaksud untuk menguji dampak lingkungan kerja fisik dan budaya organisasi dengan performa karyawan. Sehingga kedepannya diharapkan dapat memberikan konstribusi dalam memperdalam pemahaman terhadap ruang lingkup SDM terkait lingkungan kerja fisik, budaya kerja, dan performa karyawan. Selanjutnya juga bermanfaat agar mampu memberikan kontribusi dalam mengambil kebijakan agar penerapan lingkungan kerja fisik, dan budaya organisasi, pada PT. Suri Tani Pemuka dalam rangka meningkatkan performa karyawan dimasa depan.

\section{Metode}

Desain kuantitatif kausal dalam studi ini dipilih untuk membuktikan pengaruh sebuah variable satu terhadap variabel lainnya, variabel bebas studi ini ialah lingkungan kerja (X1), dan budaya organisasi (X2), dengan performa karyawan $(\mathrm{Y})$ sebagai variable terikat. Data primer studi ini merupakan data kuantitatif mengenai keadaan lingkungan kerja perusahaan, dan juga tentang budaya atau kebiasaan dalam perusahaan yang diperoleh melalui kuesioner yang dibagikan kepada karyawan PT. Suri Tani Pemuka. Skala likert dipilih pada riset ini dengan jumlah populasi total 42 orang yang merupakan karyawan PT. Suri Tani Pemuka, adapun objek riset ini ialah lingkungan kerja, budaya organisasi, dan performa karyawan. Metode survey digunakan untuk pengumpulan data, dengan teknik pengumpulan data berupa kuesioner. Selanjutnya, penulis menggunakan teknik analisis regresi linear berganda untuk menganalisis data yang diperoleh. 


\section{Hasil dan Pembahasan}

Tujuan studi ini ialah membuktikan seberapa besar pengaruh lingkungan kerja dan budaya organisasi terhadap performa karyawan PT. Suri Tani Pemuka, Pemuteran Gerokgak, Kabupaten Buleleng. Penelitian ini mencakup seluruh karyawan PT. Suri Tani Pemuka yang berjumlah 42 orang, 34 laki-laki dan 8 perempuan. Mayoritas responden adalah karyawan dengan jabatan production hatchery sebanyak 8 orang karyawan dengan persentase $19,0 \%$, sedangkan untuk jumlah responden paling sedikit adalah karyawan dengan jabatan administrasi sebanyak 2,4\%. Data tingkat pendidikan karyawan menunjukan karyawan yang berlatar belakang pendidikan SMK yang berasal dari jurusan teknik instalasi listrik, akuntansi, ilmu kemaritiman dengan persentase sebanyak 37,5\%. Sementara itu, responden yang memiliki persentase terkecil adalah karyawan yang memiliki latar belakang pendidikan setingkat sekolah dasar, dan sekolah menengah pertama dengan persentase masing-masing sebesar $2,4 \%$.

Semua instrumen kuesioner dinyatakan valid dan reliabel setelah melalui tahap pengujian. Dan pada uji asumsi klasik menyatakan data yang diperoleh normal, tidak terjadi heteroskesastisitas serta tidak ada gejala multikolinearitas. Analisis regresi linear berganda dipilih sebagai upaya untuk menjawab permasalahan dalam studi ini. teknik ini dipilih untuk mengetahui ada atau tidaknya pengaruh variabel bebas yaitu lingkungan kerja (X1), budaya organisasi (X2), terhadap variabel terikat performa karyawan (Y) pada PT. Suri Tani Pemuka, Pemuteran Gerokgak, diperoleh tabel 2 regresi sebagai berikut

Tabel 2. Koefisien Hasil Analisis Regresi

\begin{tabular}{lccccc}
\hline Model & \multicolumn{4}{c}{ Unstandarized Coefficient } & \multicolumn{3}{c}{ Standarized Coefficient } \\
\hline & $\mathrm{B}$ & Std.Error & Beta & $\mathrm{T}$ & Sig \\
1. (Constant) & 4.252 & 2.819 & & 1.508 & .140 \\
$\begin{array}{l}\text { Lingkungan kerja } \\
\text { Fisik }\end{array}$ & .385 & .107 & .445 & 3.600 & .001 \\
Budaya Organisasi & .424 & .128 & .409 & 3.305 & .002 \\
\hline
\end{tabular}

a. Dependent Variable: Kinerja Karyawan

Dapat dilihat pada Tabel 2 diperoleh nilai konstanta ( $\alpha$ ) sebesar 4,252, nilai Koefisien Regresi Lingkungan Kerja $\left(\beta_{1}\right)$ sebesar 0,385, nilai Koefisien Regresi Budaya Organisasi $\left(\beta_{2}\right)$ sebesar 0,424 , sehingga persamaan regresi diformulasikan sebagai berikut.

$$
Y=4,252+0,385 X 1+0,424 X 2+\varepsilon
$$

Berikut interpretasi hasil dari analisis:

a. Jika nilai variabel bebas sama dengan nol, maka performa karyawan $(Y)$ akan mengalami kenaikan sebesar 4.252. Dibuktikan dengan nilai Konstanta $(\alpha)$ pada tabel menunjukkan nilai 4,252.

b. Setiap kenaikan satu angka lingkungan kerja (X1) maka terjadi peningkatan 0.385 , sehinga menjadi 4.637 untuk performa karyawan $(Y)$ dengan anggapan bahwa variabel bebas yang lain tetap. Dibuktikan dengan nilai koefisien lingkungan kerja fisik $\left(\beta_{1}\right)$ pada tabel menunjukkan nilai 0,385.

c. Setiap kenaikan satu angka budaya organisasi (X2) maka terjadi peningkatan 0.424 , sehinga menjadi 4.676 untuk performa karyawan $(Y)$ dengan anggapan bahwa variabel bebas yang lain tetap. Dibuktikan dengan nilai koefisien lingkungan kerja fisik $\left(\beta_{1}\right)$ pada tabel menunjukkan nilai 0,424.

Sedangkan secara parsial, diketahui bahwa setiap variabel lingkungan kerja memiliki pengaruh positif dan signifikan terhadap performa karyawan. Dilihat dari data di atas menunjukan nilai $p$-value $0,001<$ alpha 0,05 , atau bisa dikatakan nilai sig lebih kecil dari nilai alpha 0,05 maka disimpulkan bahwa $\mathrm{H}_{0}$ ditolak, artinya terdapat pengaruh signifikan dari 
lingkungan kerja terhadap performa karyawan. Hal ini terbukti lingkungan kerja mempengaruhi peningkatan performa karyawan.

Budaya organisasi diklaim memiliki pengaruh positif dan signifikan terhadap performa karyawan. Hal ini dilihat dari table dimana nilai $p$-value $0,002<$ alpha 0,05 , atau bisa dikatakan nilai sig lebih kecil dari nilai alpha 0,05 maka disimpulkan bahwa $\mathrm{H}_{0}$ ditolak, artinya terdapat pengaruh positif yang signifikan dari budaya organisasi terhadap performa karyawan. Hal ini terbukti bahwa variabel budaya organisasi memiliki peran dalam upaya meningkatkan performa karyawan.

Terdapat pengaruh positif dan signifikan terhadap performa karyawan oleh lingkungan kerja dan budaya organisasi. Hal ini dibuktikan dari tabel yang tertera pada halaman sebelumnya, dimana nilai koefisien determinasi $\mathrm{Ryx}_{1} \mathrm{x}_{2}$ sebesar 0,735 dengan tanda positif, dengan nilai $p$-value $0,000<$ alpha 0,05 , artinya nilai sig lebih kecil dari nilai alpha 0,05 maka disimpulkan bahwa $\mathrm{HO}$ ditolak, artinya lingkungan kerja dan budaya organisasi berpengaruh terhadap performa karyawan. 0.541 (54.1\%) perfroma karyawan dipengaruhi oleh lingkungan kerja dan budaya organisasi dan $45,9 \%$ sisanya dipengaruhi oleh variabel lainnya.

Berdasarkan hasil riset, variabel lingkungan kerja dan budaya organisasi berdampak positif dan signifikan terhadap performa karyawan. Temuan ini didukung oleh Mangkunegara (2006), yang menunjukkan adanya hubungan antara lingkungan kerja dan performa karyawan sanglah erat.

Hasil analisis juga membuktikan bahwa motif berprestasi dalam diri dan lingkungan kerja juga perlu dimiliki oleh karyawan untuk membentuk suatu kekuatan. Tentunya harus didukung dengan lingkungan kerja yang baik demi mudahnya mencapai performa kerja.

Temuan ini mendukung yang hasil penelitian yang dilakukan oleh Wahyuniardi, dkk (2018), Prahasti dkk (2018), serta Dwiarti dkk (2018) yang mengemukakan bahwa lingkungan kerja berpengaruh secara signifikan terhadap performa. Wahyuniardi (2018) menerangkan bahwa lingkungan kerja mencakup keseluruhan alat, bahan, metode serta pengaturan kerja yang terdapat di lingkungan di mana orang bekerja. Semakin nyaman karyawan dalam bekerja akan semakin meningkat performa yang dihasilkan oleh karyawan tersebut.

Selanjutnya, hasil studi ini juga menunjukkan adanya pengaruh positif dan signifikan antara budaya organisasi dan performa karyawan. Secara tidak langsung budaya organisasi pada suatu perusahaan mampu mendorong karyawan untuk meningkatkan prestasi dan performa mereka. Banyak ahli organisasi dan peneliti mengklaim, bahwa efek jangka panjang dari budaya organisasi terhadap performa dan efektivitas organisasi sangat kuat.

Hal ini berarti, semakin baik budaya atau kebiasaan yang diterapkan dalam suatu organisasi dapat meningkatkan performa karyawan yang menempatinya. Hasil tersebut juga sejalan dengan Wahyuniardi, dkk (2018), Prahasti, dkk (2018), Perawati, dkk (2018), Noor dkk (2012), Sutrisno (2009), serta Wanjiku dkk (2014) yang menyimpulkan bahwa budaya organisasi yang baik dan teratur dapat membantu karyawan mengatur performa agar tujuan organisasi mudah dicapai. Lebih jauh, Noor (2012) menekankan bahwa budaya organisasi menjadi faktor krusial suatu organisasi, karena menentukan suatu kebiasaan suatu organisasi dan berpengaruh terhadap cara berkomunikasi, mengambil keputusan dan memimpin, tingkat keefektivitasan organisasi dapat dicapai dengan terciptanya budaya organisasi yang baik.

\section{Simpulan dan Saran}

Berdasarkan hasil analisis terdapat tiga kesimpulan yang menjawab permasalahan pada studi ini. Satu, lingkungan kerja berdampak positif terhadap performa karyawan PT. Suri Tani Pemuka. Dua, budaya organisasi memiliki dampak positif terhadap performa karyawan PT. Suri Tani Pemuka. Tiga, lingkungan kerja dan budaya organisasi memiliki dampak positif signifikan terhadap performa karyawan PT. Suri Tani Pemuka.

Adapun saran yang dari peneliti pada penelitain ini yakni periset di bidang yang sama dapat menguji pengaruh variabel lain terhadap performa seperti, disiplin kerja dan kepemimpinan. Penelitian selanjutnya dapat dikembangkan dalam konteks lain dengan ruang lingkup serta jumlah sampel yang lebih luas. Diharapkan petinggi dari PT.Suri Tani Pemuka memahami permasalahan ini dengan cermat dan segera mengambil tindakan yang telah peneliti cantumkan pada bagian implikasi penelitian. Semoga dengan penerapan tersebut 
mampu menimbulkan dan meningkatkan performa karyawan PT.Suri Tani Pemuka, sehingga target yang ditentukan perusahaan dapat tercapai dengan maksimal.

\section{Daftar Pustaka}

Dwiarti dan Wibowo (2018), "Analisis Pengaruh Tingkat Pendidikan, Kompensasi, Dan Lingkungan Kerja Terhadap Kinerja Karyawan pada PT. Taman Wisata Candi Prambanan.". Jurnal Perilaku dan Strategi Bisnis, Vol 06, Iss 2, Pp 157-170, ISSN: 2337-5817

Mangkunegara, (2001). Perencanaan dan Pengembangan Sumber Daya Manusia. Bandung: Refika Aditama.

Noor, Zainul Arifin (2012), "Pengaruh Budaya Organisasi, Komitmen Organisasi, dan Motivasi Kerja terhadap kepuasaan Kerja dan Kinerja Karyawan”. Jurnal Ekonomi dan Keuangan. ISSN:1411-0393

Perawati, Komang Mas, dkk (2018), "Pengaruh Gaya Kepemiampinan Transformasional, Budaya Organisasi, dan Komitmen Organisasi pada Kinerja Organisasi”. E-Jurnal Akuntansi Universitas Udayana.- Vol.25. No.03 ISSN: 2302-8556

Prahasti, Shella, dkk. (2018), "Pengaruh Gaya Kepemimpinan, Budaya Organisasi, dan Lingkungan Kerja terhadap Kinerja Pegawai dengan Kepuasan Kerja sebagai Mediator" EEAJ-Vol.07 No.02, ISSN: 2254-6544

Riani, Asri Laksmi. (2011). Budaya Organisasi. Jogjakarta: Graha IImu

Robbins, Stephen P. (2006). Perilaku Organisasi. Jakarta: PT Indeks Kelompok Gramedia.

Saputri, Muhsin (2019), "Peran Komitmen Organisasi Dalam Memediasi Pengaruh Variabel Keteladanan Pemimpin, Kompetensi Perangkat Desa, dan Budaya Organisasi Terhadap Kinerja", EEAJ-Vol.07 No.03, ISSN: 2502-356X

Sedarmayanti. (2007). Sumber Daya Manusia dan Produktivitas Kerja. Bandung: CV.Mandar Maju

Sri Noviani, Widhiani (2018), "Pengaruh Gaya Kepemimpinan Situasional, Motivasi, dan Pelatihan pada Kinerja Karyawan di Koperasi Pasar Srikandi Klungkung". E-Jurnal Akuntansi Universitas Udayana-Vol.25. No.03, ISSN: 2212-2241

Sunyoto, Danang. (2012). Teori, Kuesioner, dan Analisis Data Sumber Daya Manusia (Praktik Penelitian). Yogyakarta: CAPS (Center for Academics Publishing Service)

Sutrisno, Edy, (2009). "Pengaruh Budaya Organisasi, Stres Kerja, dan Komitmen terhadap Kinerja Karyawan CV. Bintang Karya Putra di Surabaya". Ekuitas Vol.14 No.04:460 477, ISSN: 1411-0393

Vita, Bernadine, (2014)."Pengaruh Gaya Kepemimpinan, Budaya Organisasi, dan Lingkungan Kerja terhadap Kinerja Guru dan Karyawan pada Yayasan Tri Asih Jakarta". Jurnal Ekonomi Universitas Atma Jaya Yogyakarta, Vol 43. No. 05, ISSN: 3247- 6744

Wahyuniardi dan Nurjaman, (2018). "Pengaruh Budaya Organisasi dan Lingkungan Kerja terhadap Kepuasan Kerja dan Kinerja Karyawan”. Jurnal Optimasi Sistem Industri. Vol 17, Pp 143-151, ISSN: 2088-4842 
Wanjiku dan Nickson, (2014). " Effect of Organisation culture on Employee Performance in Non Govermantal Organization”. International Journal of Scientific and research Publications. Volume 04 Issue 11, November 2014, ISSN: 2250-3153

Wibowo. (2010). Budaya Organisasi. Depok: Raja Grafindo Persada 